\title{
Identifying Healthcare Management Obstacles Through The Eyes Of Healthcare Managers
}

\author{
Wye Lee Chiew ${ }^{1}$ \\ Department of Community Health, \\ Faculty of Medicine, UniversitiKebangsaan Malaysia, \\ JalanYaacobLatif, Cheras, 56000 Kuala Lumpur, Malaysia \\ drchiew@outlook.com
}

\author{
Aniza Ismail ${ }^{2}$ \\ Department of Community Health, \\ Faculty of Medicine, UniversitiKebangsaan Malaysia, \\ JalanYaacobLatif, Cheras, 56000 Kuala Lumpur, Malaysia \\ draniza@gmail.com
}

\begin{abstract}
The demand for healthcare services often exceeds available resources, yet healthcare managers were expected to deliver better healthcare services. Healthcare management obstacles could either make or break the healthcare manager and bring about a few kinds of performance outcome; successful, mediocre outcome or failure. The aim of the study was to identify the factors of healthcare management obstacles and the healthcare managers' perceptions of their ability to cope with these obstacles. Doctors in management answered self-administered driver of managerial questionnaires on rules, initiatives, emotions, immediate actions and integrity. Data were analysed using descriptive analysis and linear regression. Immediate action posed the hardest obstacles to cope. Emotions were perceived as the easiest obstacles to cope. Duration as manager was a significant factor to bring about lower obstacles to driver of rules $(b=0.02, p<0.05)$ and driver of initiatives $(b=0.02, p<0.05)$. Working in the health office was significantly perceived to have higher obstacles to emotions $(b=$ $\mathbf{- 0 . 1 8}, \mathbf{p}<\mathbf{0 . 0 5})$. Healthcare manager perceived obstacles encountered, in descending order of difficulty, are immediate actions, rules, initiatives, integrity and lastly emotions. The findings from this study provide insights as to what was needed to strengthen in overcoming obstacles in healthcare management.
\end{abstract}

Keywords - healthcare obstacle; management obstacle; healthcare manager

\section{INTRODUCTION}

Effective leadership can overcome obstacles of healthcare management and propelled an organisation towards success. Healthcare cost in Malaysia is affordable and accessible [1]. The need to control runaway healthcare costs and to meet the population demands for access to universal care was the top issues for the public sector [2]. To ensure sustain advances in healthcare delivery, workforce performance should be given emphases. The workforce, in particular the doctors who manage the Malaysia healthcare facilities are leaving and this will cause a big negative impact on the Malaysian healthcare system.

Doctors have the credibility to manage healthcare facilities, having trained form undergraduate as the caregiver, manager and leader. Goodall's study found that the best-performing hospitals are lead by doctors [3].
However, few venture into healthcare management. Management role is insecure and there is no clear career pathway direction in healthcare management. The high level of accountability and work load are obstacles of healthcare management [4]. Obstacles, which are gaps between organisation's objectives and its reality, are present on daily basis for the healthcare managers [5]. Thus, healthcare managers' performances may range from success to failure.

From the study of literature review on management, empirical work on the 1984 Kolb model as well as Sabourine's work, there exist five dimensions of management obstacles: the drivers of rules, emotions, initiatives, immediate action and integrity [6]. Rules are the clarity and acceptance of the manager's objectives for the organisation. Examples of obstacles towards rules are the resistance towards implementation of unpopular policies and use of resources, authority conflict, personal and organisational values disagreement or being challenged by others. Emotion is the ability in getting the commitment of others to collaborate with manager's objectives. Example of obstacles of emotions is the fear of managing others or being alienated from colleagues. Initiative is the impediments that healthcare manager faced when initiating new changes. Immediate actions is the ability to anticipate and act upon emergencies when faced with obstacles. Integrity will have the healthcare manager upholding principles and values in response to obstacles while preserving own mandate.

Age appeared to exert more influence than gender and ethnicity. Younger doctors were perceived having better technical skills and personality [7]. In the Information Technology era, the young managers have the advantage using technology to address the business needs of the organisation [8].

Women face higher organisation challenges. Middle management is more likely run by women, whereas higher management is mainly by men [9],[10]. A study on women leaders in US healthcare found that women faced more obstacles [11]. Unlike Shah and Ogden study, their study found that gender exert more influence than race or ethnicity in climbing the manager posts. Chin et al. study found that there are no significant effects of gender, but the more androgynous and transformational the more successful the leaders [12]. 
Healthcare organisation has a heterogeneous workforce. Minority healthcare managers would understand better minority ethnic workforce and patients[13]. Leaders who are similar to their subordinates face lesser obstacles from their subordinates' commitments [14]. In a heterogeneous workforce where the majority of the subordinates ethnicity differs, the obstacles might be more compared to having a homogenous subordinate. Despite that possibility, demographic diversity, leadership could lead to better outcomes by enhancing creativity and promoting better group problem solving [15].

The healthcare facilities in Malaysia are managed by doctors. Preferences to healthcare managerial posts are given to those with postgraduate qualification in public health and hospital administration. A recent study on the academic workforce found that senior post is given to those who has proven themselves through their performance, had high job satisfaction and those who are can accommodate themselves to the facilities. Those with professional qualification have an added advantage [16]. However, there were many settings where those who have served for a length of time are appointed to senior posts [17]. To a large extent the public healthcare sector in Malaysia did just that. The assumption that the longer a person has served in a field will allow him to observe and learn how to overcome obstacles [18].

The higher the level of management, the bigger will be the obstacles. Issues arise if the healthcare managers are ill prepared. If the healthcare managers are unable to cope with the obstacles, the job related outcomes will be poor [19].

Healthcare managers encountered numerous obstacles. It is therefore crucial to identify the obstacles in managing healthcare that could result in a vacuum in the public healthcare system. Information about factors that could influence obstacles could be useful for future managerial development. Thus the aim of the study is to identify the obstacles of healthcare management; and to determine the factors associated with obstacles of healthcare management.

\section{METHOD}

The data of this cross sectional study were obtained from universal sampling of healthcare managers of five states in Malaysia. The states involved selected by purposive sampling are Perlis, Kedah, Pulau Pinang, Selangor and Kuala Lumpur. From January to Jun 2016, healthcare managers who have worked a minimum of one year in management were approached personally toparticipate in the survey. For a survey of this nature the response rate of $69.3 \%$ of the sample was considered high. There were no particular response bias as the responses were received from the full range of public healthcare facilities; the state health departments, public hospitals and district health offices.

The validated questionnaire consists of five factors that were identified as obstacles of healthcare management. The self-administered questionnaire was conducted in English as healthcare managers are proficient in English. During the pilot study with one hundred and fifty respondents, exploratory factor analysis was conducted. The 25 items on the questionnaire were subjected to principal component analysis were then reduced to fifteen items. The Cronbach alpha for the questionnaire with the fifteen items was 0.925 . Rules has item D1 and D2. Driver of emotions has item D3, D4 and D5. Initiatives has item D6, D7 and D8. Driver of immediate actions has item D 9, D10 and D11. Integrity has item D12, D13, D14 and D15.

The respondents answered by self-assessment their perceived ability to cope with obstacles of healthcare management. The likert scale score range from score 1 denoting strongly disagreed to score 5 meaning strongly agree. As the items were worded positive in nature, any disagreement with the statement meant they perceived obstacles.

The data were analysed using Statistical Package for Social Sciences software version 21.0. Descriptive statistic in frequency and percentage was used to report The sociodemographic characteristics was shown in descriptive statistic and linear regression analysis was then utilized to determine the associated factors with challenges.

\section{RESULTS}

On an average the healthcare managers was 43 years with 17 years in service and 7 years in management. The number of undergraduates and postgraduates was about the same. $48.1 \%$ were working in the health, $34.1 \%$ in hospitals and $17.8 \%$ were with the state department.

For the healthcare managers, the lowest mean score $(3.54 \pm 0.74)$ was driver of immediate actions, which meant that having to deal with immediate action was perceived as the highest obstacles. This was followed by driver of rules $(4.04 \pm 0.54)$, driver of initiatives $(4.10 \pm 0.51)$ and driver of emotions $(4.12 \pm 0.52)$. The healthcare managers perceived that they could cope with obstacles of integrity, which had the highest score $(4.13 \pm 0.49)$. 
TABLE I

FACTOR ASSOCIATED WITH RULES $(\mathrm{n}=208)$

\begin{tabular}{|c|c|c|c|c|c|c|c|}
\hline \multirow{2}{*}{ Factor } & \multicolumn{2}{|c|}{ Unstandardized Coefficients } & \multirow{2}{*}{$\begin{array}{c}\text { Standardized Coefficients } \\
\text { Beta }\end{array}$} & \multirow[t]{2}{*}{$t$} & \multirow[t]{2}{*}{ Sig. } & \multicolumn{2}{|c|}{$95 \%$ Confidence Interval for B } \\
\hline & $\mathrm{B}$ & Std. Error & & & & Lower Bound & Upper Bound \\
\hline (Constant) & 3.988 & .331 & & 12.055 & .000 & 3.336 & 4.641 \\
\hline Female & -.054 & .072 & -.054 & -.751 & .454 & -.197 & .088 \\
\hline Non Malay & .021 & .075 & .020 & .275 & .784 & -.127 & .168 \\
\hline Undergrad & .014 & .076 & .015 & .189 & .850 & -.136 & .164 \\
\hline Hospital & -.082 & .104 & -.082 & -.794 & .428 & -.287 & .122 \\
\hline Health & -.067 & .096 & -.071 & -.700 & .484 & -.258 & .123 \\
\hline Age & .002 & .011 & .029 & .171 & .865 & -.019 & .023 \\
\hline Length service & -.005 & .011 & -.078 & -.450 & .653 & -.026 & .016 \\
\hline Duration as manager & .020 & .008 & .257 & 2.398 & .017 & .003 & .036 \\
\hline
\end{tabular}

R square 0.059

Reference group: Male, Malay, Postgraduate, State Health Department

TABLE II

FACTOR ASSOCIATED WITH EMOTIONS $(\mathrm{n}=208)$

\begin{tabular}{|c|c|c|c|c|c|c|c|}
\hline \multirow{2}{*}{ Factor } & \multicolumn{2}{|c|}{ Unstandardized Coefficients } & \multirow{2}{*}{$\begin{array}{c}\text { Standardized Coefficients } \\
\text { Beta }\end{array}$} & \multirow{2}{*}{$\mathrm{t}$} & \multirow{2}{*}{ Sig. } & \multicolumn{2}{|c|}{ 95\% Confidence Interval for B } \\
\hline & B & Std. Error & & & & Lower Bound & Upper Bound \\
\hline (Constant) & 4.714 & 0.315 & & 14.983 & 0 & 4.094 & 5.334 \\
\hline Female & -0.033 & 0.069 & -0.034 & -0.48 & 0.632 & -0.168 & 0.103 \\
\hline Non Malay & -0.056 & 0.071 & -0.057 & -0.788 & 0.432 & -0.196 & 0.084 \\
\hline Undergrad & -0.034 & 0.072 & -0.037 & -0.466 & 0.642 & -0.176 & 0.109 \\
\hline Hospital & -0.056 & 0.099 & -0.058 & -0.567 & 0.572 & -0.25 & 0.139 \\
\hline Health & -0.184 & 0.092 & -0.203 & -2.01 & 0.046 & -0.365 & -0.004 \\
\hline Age & -0.013 & 0.01 & -0.21 & -1.237 & 0.218 & -0.033 & 0.007 \\
\hline Length service & 0.005 & 0.01 & 0.085 & 0.491 & 0.624 & -0.015 & 0.025 \\
\hline Duration as manager & 0.013 & 0.008 & 0.176 & 1.653 & 0.100 & -0.002 & 0.028 \\
\hline
\end{tabular}

$\mathrm{r}$ square $=0.060$

Reference group: Male, Malay, Postgraduate, State Health Department

TABLE III

FACTOR ASSOCIATED WITH INITIATIVES $(\mathrm{n}=208)$

\begin{tabular}{|c|c|c|c|c|c|c|c|}
\hline \multirow[t]{2}{*}{ Factor } & \multicolumn{2}{|c|}{ Unstandardized Coefficients } & \multirow{2}{*}{$\frac{\text { Standardized Coefficients }}{\text { Beta }}$} & \multirow[t]{2}{*}{$\mathrm{t}$} & \multirow[t]{2}{*}{ Sig. } & \multicolumn{2}{|c|}{$95 \%$ Confidence Interval for B } \\
\hline & $\mathrm{B}$ & Std. Error & & & & Lower Bound & Upper Bound \\
\hline (Constant) & 4.469 & 0.36 & & 12.43 & 0 & 3.76 & 5.178 \\
\hline Female & -0.052 & 0.079 & -0.048 & -0.67 & 0.505 & -0.207 & 0.102 \\
\hline Non Malay & -0.014 & 0.081 & -0.013 & -0.18 & 0.859 & -0.174 & 0.146 \\
\hline || Undergrad & -0.029 & 0.083 & -0.028 & -0.35 & 0.727 & -0.192 & 0.134 \\
\hline Hospital & -0.064 & 0.113 & -0.06 & -0.57 & 0.568 & -0.287 & 0.158 \\
\hline Health & -0.067 & 0.105 & -0.066 & $\begin{array}{l}-0.64 \\
\end{array}$ & 0.523 & -0.274 & 0.139 \\
\hline Age & -0.01 & 0.012 & -0.15 & -0.87 & 0.386 & -0.033 & 0.013 \\
\hline Length service & 0.001 & 0.012 & 0.008 & 0.047 & 0.963 & -0.023 & 0.024 \\
\hline Duration as manager & 0.018 & 0.009 & 0.22 & 2.026 & 0.044 & 0 & 0.036 \\
\hline
\end{tabular}

Duration

Reference group: Male, Malay, Postgraduate, State Health Department

TABLE IV

FACTOR ASSOCIATED WITH IMMEDIATE ACTIONS $(\mathrm{n}=208)$

\begin{tabular}{|c|c|c|c|c|c|c|c|}
\hline \multirow[t]{2}{*}{ Factor } & \multicolumn{2}{|c|}{ Unstandardized Coefficients } & \multirow{2}{*}{$\begin{array}{c}\text { Standardized Coefficients } \\
\text { Beta }\end{array}$} & \multirow[t]{2}{*}{$\mathrm{t}$} & \multirow[t]{2}{*}{ Sig. } & \multicolumn{2}{|c|}{$95 \%$ Confidence Interval for B } \\
\hline & B & Std. Error & & & & Lower Bound & Upper Bound \\
\hline (Constant) & 4.297 & 0.418 & & 10.29 & 0 & 3.474 & 5.121 \\
\hline Female & 0.011 & 0.091 & 0.009 & 0.119 & 0.906 & -0.169 & 0.191 \\
\hline Non Malay & 0.053 & 0.094 & 0.041 & 0.562 & 0.575 & -0.133 & 0.239 \\
\hline Undergrad & 0.02 & 0.096 & 0.017 & 0.210 & 0.834 & -0.169 & 0.21 \\
\hline Hospital & -0.164 & 0.131 & -0.132 & -1.26 & 0.211 & -0.422 & 0.094 \\
\hline Health & -0.201 & 0.122 & -0.17 & -1.66 & 0.099 & -0.441 & 0.039 \\
\hline Age & -0.013 & 0.013 & -0.162 & -0.94 & 0.350 & -0.039 & 0.014 \\
\hline Length service & 0.001 & 0.014 & 0.007 & 0.039 & 0.969 & -0.026 & 0.027 \\
\hline Duration as manager & 0.017 & 0.01 & 0.179 & 1.643 & 0.102 & -0.003 & 0.037 \\
\hline
\end{tabular}

$\mathrm{r}$ square $=0.34$

Reference group: Male, Malay, Postgraduate, State Health Department 
TABLE V

FACTOR ASSOCIATED WITH INTEGRITY $(\mathrm{n}=208)$

\begin{tabular}{|c|c|c|c|c|c|c|c|}
\hline \multirow{2}{*}{ Factor } & \multicolumn{2}{|c|}{ Unstandardized Coefficients } & \multirow{2}{*}{$\frac{\text { Standardized Coefficients }}{\text { Beta }}$} & \multirow[t]{2}{*}{$\mathrm{t}$} & \multirow[t]{2}{*}{ Sig. } & \multicolumn{2}{|c|}{$95 \%$ Confidence Interval for B } \\
\hline & B & Std. Error & & & & Lower Bound & Upper Bound \\
\hline (Constant) & 4.266 & .344 & & 12.384 & .000 & 3.587 & 4.945 \\
\hline Female & -.010 & .075 & -.009 & -.129 & .897 & -.158 & .139 \\
\hline Non Malay & .036 & .078 & .034 & .469 & .639 & -.117 & .190 \\
\hline Undergrad & -.068 & .079 & -.069 & -.858 & .392 & -.224 & .088 \\
\hline Hospital & -.124 & .108 & -.119 & -1.147 & .253 & -.337 & .089 \\
\hline Health & -.158 & .100 & -.160 & -1.574 & .117 & -.356 & .040 \\
\hline Age & -.002 & .011 & -.037 & -.218 & .828 & -.024 & .019 \\
\hline Length service & -.001 & .011 & -.010 & -.059 & .953 & -.023 & .022 \\
\hline Duration as manager & .015 & .009 & .183 & 1.703 & .090 & -.002 & .031 \\
\hline
\end{tabular}

r square $=0.55$

Reference group: Male, Malay, Postgraduate, State Health Department

Table I-V shows the factors associated with rules, emotions, initiatives, immediate actions and integrity. There is only one factor associated with driver of rules that is the duration as manager. Rules $=3.988+0.02$ (duration as manager), $\mathrm{p}=0.017,95 \%$ CI $0.003-0.036$. For the driver of emotions, the factor involved place of work. Using the state health department as the reference group, district health office was a significant factor, but hospital was found having no significant with emotions. Emotions $=4.714$ 0.184 (district health office), $\mathrm{p}=0.046,95 \%$ CI -0.365 , 0.004 . Duration as manager is associated with initiatives. Initiatives $=4.469+0.018$ (duration as manager), $\mathrm{p}=0.044$, $95 \%$ CI $0,0.036$. However, there was no factor associated with immediate actions or with integrity.

\section{DISCUSSION}

There were five drivers of obstacles; rules, emotions, initiatives, immediate actions and integrity.

The healthcare managers find obstacles of immediate actions was the most difficult. This finding was similar to a Canadian study among IT managers [20]. Immediate actions require making decisions and acting on it in responding to an issue. On some occasions, having to act immediately can be an obstacle, when there is hesitant in decision making and implementing an action. The decision making process is a tedious multistage process, involving all levels and all areas of organizations; and having to take into consideration legal, social, technological, infrastructure constraints. There was no factor associated with immediate actions. Duration in service and duration as a manager were thought to provide the advantages of experience in taking immediate actions in responding to an obstacle, however the study showed no significant of duration in service or duration as a healthcare manager.

The lowest perceived obstacle was towards emotions. Emotions obstacles are conceptualised as self investment into their roles as healthcare managers. The healthcare managers were able to appeal to others to collaborate and realised their objectives and the organisation's objectives. It appeared that there is organising supports behind the healthcare managers. Where there is organising support, there will be a better task performance and performance outcomes [21]. Place of work was found significant with emotions. District health office compared to state health department face higher emotions obstacles. Hospital was not significant. Emotions obstacles deal with fetching a commitment, clarifying problems, reconciling the divergent points of view and establishing consensus. Healthcare managers working in the health office often deal with the community and with a wide scope of community issues. Healthcare managers working in the district health office have to appeal to the emotional aspect of those they work with. Communication skills and people skills are needed, failing which the emotions obstacles of healthcare will be difficult to overcome.

As for the obstacles rules, duration as manager was significant. The longer the duration as manager will lower the obstacles of rules. Rules are defined as the clarity and the alignment of the healthcare managers' objectives. Any well structured policies are needed for a positive performance impact, thus rules are important. The duration as a manager prepares the healthcare manager with work experiences, which facilitates work performancesand overcoming any rules obstacles [6].

Similarly with initiatives obstacles, it was the duration as manager that was significant. Initiatives involve introducing new ideas in more willing employees. Initiatives are not always welcome as it involves changes and putting up with risks. Risk-taking is a critical factor in the development of a business. Given the nature of healthcare managerial impediments, there will be resistant towards initiating new changes. Senior healthcare managers by their service as managers, face lower initiatives obstacles because the experience gained makes them more confident initiating moves and taking risks. The developmental maturation of the healthcare manager accelerates more quickly between mid-career and senior leadership [22]. Appointing a young doctor to the post as healthcare manager, will have the young doctor facing a high amount of obstacles, partly due to age factor and the lack of experience.

Integrity was the least concerned of the obstacles. Integrity was defined as ability in executing objectives in respecting organizational values and principles. The respondents were able to carry out their duties without 
compromising integrity, exercising ethics, honesty and transparency within themselves and their teams. A professional moral role often poses conflicts between organisational expectations and self performances [23]. Upbringing, religion and education could be a contributor to the integrity, values within the healthcare managers. This remains to be furthered studied.

\section{CONCLUSIONS}

The study has identified specific refined obstacle model for organisation management. The information can be used for practical training and development of healthcare managers. Obstacles of healthcare management are rules, emotions, immediate actions, initiatives and integrity. Duration as a manager and working at health office are significant factors of obstacles of healthcare management. Healthcare managers require training and experience to cope with obstacles of healthcare management.

The factors involved in the study contribute to a small portion of the obstacles. Other possible factors like competency and training need to be studied. There could be bias since the survey was by self assessment, possibility of overestimating their coping ability could have occurred. Additional work involving whole nation is required to generalize the findings.

\section{ACKNOWLEDGMENT}

The authors would like to acknowledge all participants, the Ministry of Health Malaysia, State Health Department directors, hospital directors and district health officers.

\section{REFERENCES}

[1] V. Kumar, A. K. Duncan, and M. A. Breslin, "Innovating Health Care Delivery: The Design of Health Services,"Journal of Business Strategy, 30(2/3), pp. 13-20, 2009.

[2] Deloitte, Global health care outlook: Shared challenges, shared opportunities, Deloitte Touché Tohmatsu Limited, 2014

[3] A. H. Goodall."Physician-Leaders and Hospital Performance: Is There an Association?,"Social Science \& Medicine, vol. 73(4), pp. 535-539, 2011

[4] S. K. Ireri, "A Comparative Study of Experiences, Competencies and Development Needs of Doctor Managers in Kenya and the United Kingdom," Thesis University of Manchester. 2011a.

[5] E. Van Velsor, "Learning new ways: A conversation with Ronald A. Heifetz," Leadership in Action, 23(1), 19-22. 2003. Retrieved from Business Source Complete database.
[6] V. Sabourin, "Healthcre Management and Leadership. Managerial Challenges Facing Healthcare Professionals,"Europian Journal of Business and Management, vol. 3(7), pp. 18-35, 2011.

[7] R. Shah, and J. Ogden. 2006. 'What's in a Face? The Role of Doctor Ethnicity, Age and Gender in the Formation of Patients' Judgements: An Experimental Study,"Patient Education and Counseling, vol. 60(2), pp. 136-141, 2006.

[8] G. Ekaterini, "The impact of leadership styles on four variables of executives workforce,"International Journal of Business and Management, vol. 5(6), pp. 3-16, 2001.

[9] A. Agogino, Beyond bias and barriers: Fulfilling the potential of women in academic science and engineering, APS April Meeting Abstracts, hl,. 6001. 2007.

[10] P.M. Lantz, "Gender and Leadership in Healthcare Administration: 21st Century Progress and Challenges,"Journal of Healthcare Management . vol. 53(5), pp. 291-301, 2008.

[11] D. Salas-Lopez, L. M. Deitrick, E. T. Mahady, E. J. Gertner, and J. N. Sabino, "Women Leaders - Challenges, Successes, and Other Insights from the Top,"Journal Of Leadership Studies, vol. 5(2), pp. 34-42, 2011.

[12] J. L. Chin, B. Lott, J. Rice, and J. Sanchez-Hucles, "Women and Leadership: Transforming visions and diverse voices". Main Street, Malden, Blackwell Publishing.

[13] J. R. Betancourt, S. Beiter, A. Landry, "Improving quality, achieving equity, and increasing diversity in healthcare: the future is now". Journal of Best Practices in Health Professions Diversity: Research, Education and Policy, vol. 6, pp. 903-917, 2013.

[14] Z. Zhang, M. Wang, andJ. Shi, "Leader-Follower Congruence in Proactive Personality and Work Outcomes: The Mediating Role of Leader-Member Exchange". Academy of Management Journal, vol 55(1), pp.111-130, 2012.

[15] E. Dotson, andA. Nuru-Jeter, "Setting the Stage for a Business Case for Leadership Diversity in Healthcare: History, Research, and Leverage,"Journal of Healthcare Management, vol. 57(1), pp. 3544, 2012.

[16] J.F.L. Jackson, andE.M. O'Callaghan, "Understanding Employment Disparities Using Glass Ceiling Effects Criteria: An Examination of Race/Ethnicity and Senior-Level Position Attainment across the Academic Workforce.'The Journal of the Professoriate, vol. 5(2), pp. 68, 2011.

[17] S. French, "Challenges to Developing and Providing Nursing Leadership,"Canadian Journal of Nursing Leadership, vol 17(4), pp. 37-40, 2004.

[18] M. Harris, A. Von Keudell, G. McMahon, and B. Bierer,"Physician Self-Assessment of Leadership Skills,"Physician Executive, vol. 40(2), pp. 30-36, 2014.

[19] S.E. Anderson, B.S. Coffey, andR.T. Byerly, "Formal organisational initiatives and informal workplaces: Links to work-family conflict and job-related outcomes, “ Journal of Management, vol 28(6), pp. 787-810, 2002.

[20] S. Vincent, "Management Practices: An Analysis of Gender Differences in the Strategy Execution,"African Journal of Business Management, vol 6(7), pp. 2467, 2012.

[21] B.L. Rich, J.A. Lepine, and E.R. Crawford, "Job engagement: Antecedents and effects on job performance," Academy of management Journal, vol. 53(3), pp.617-635. 2010.

[22] V. Clerveaux, T. Katada, and K. Hosoi, Informaiton Simulation Model: Effective Comunication and Disaster Management in a Mixed-Cultural Society. Tesis2009.

[23] A. Cribb, "Integrity at Work: Managing Routine Moral Stress in Professional Roles,"Nursing Philosophy, vol. 12(2), pp. 119-127. 2011. 